\title{
Spasticity Measurement
}

\author{
Belgin PETEK BALCID
}

Department of Neurology, Faculty of Medicine, University of Health Sciences; Haseki Research and Education Hospital Neurology Clinic, İstanbul, Turkey

\section{ABSTRACT}

Spasticity is a serious problem that adversely affects the daily life of patients, and creates difficulties for caregivers. The symptom that causes the most disability in multiple sclerosis patients is spasticity. The methods used in the measurement and evaluation of spasticity have some incomplete aspects and errors. In this article, we examined and compared the old and new methods used in the quantitative evaluation of spasticity, and tried to define the ideal method.

Keywords: Spasticity measurement, spasticity assessment, multiple sclerosis, spasticity scales, rating scales

Cite this article as: Balcı BP. Spasticity Measurement. Arch Neuropsychiatry 2018;55: (Suppl 1):S49-S53. https://doi.org/10.29399/npa.23339

\section{INTRODUCTION}

Spasticity is a serious problem that creates difficulty for both patients and caregivers. Spasticity is the most common cause of disability in multiple sclerosis (MS) patients with more than $80 \%$ patients suffering from it during the entire course of the disease (1). It has been defined in many ways over the years; however, the definition by Lance in 1980 is the most accepted one. Accordingly, spasticity is a motor disorder characterized by an increase in the tonic-stretch reflexes due to hyperexcitability tensions, resulting from the hyperexcitability of the stretch reflex, as a component of the upper motor neuron syndrome (2). Later, other characteristics of upper motor neuron syndrome were added to this definition (2). Finally, the Spasticity Study Group "SPASM" (Support Programme for Assembly of a database for Spasticity Measurement) has made the term of spasticity more practical by defining it as "a sensorimotor control disorder that emerges as a result of upper motor neuron syndrome and in the form of muscles' involuntary intermittent or permanent activation" (3).

Spasticity occurs as a result of the damage of myelin and axonal fibres, and as a result of the deterioration of upper neuron stretch reflex. Three major mechanisms that are connected to upper motor neuron lesion play role in the development of spasticity. These mechanisms are the changes of afferent input coming to spinal motor neurons, the changes in reflex arcs that affect motor neurons' excitability and the changes of motor neurons' internal features (4).

Spasticity may be common and severe in demyelinating diseases, especially in MS; this causes patients' experiencing hypertonus, clonus, flexor and extensor spasms. Spasticity appears in different forms in accordance with the lesion's place, origin time and size (5). It is known that many factors may stimulate spasticity; a few of these factors are fever and exercise that may cause an increase in body temperature, the usage of IFN-beta, the sudden heat and moisture changes in the environment, infections, bladder and bowel problems, fractures, burns, pressure sores, dressing tightly, stress-emotional disorders, the progression of MS (6).

\section{Spasticity Measurement Methods}

Although spasticity is a well-known disorder, the measurement and evaluation processes are still problematic (7). Many methods for spasticity measurement have been developed; they can be separated into two groups as the clinical evaluation methods and quantitative evaluation methods.

The clinical evaluation of spasticity begins with the detailed history and physical examination. In this phase, the duration, frequency and severity of spasticity, the quality of sleep, the drugs taken, additional diseases, which muscle groups are affected, if the spasticity is useful or harmful for the patient, facilitating factors and whether there is a pain or not are investigated. Afterwards, physical examination begins. In this phase, the existence and frequency of flexor or extensor spasms are investigated and recorded, the posture analysis is made. Later, muscle tone and tendon reflexes are examined. Muscle tone is evaluated when the patient is comfortable and relaxed in the supine position for both lower extremities and in upper extremities separately. Clonus, triple flexion reflex, sole skin reflex and other pathological reflexes, passive and active joint range of motion, voluntary muscle strength, contractures and functional loss are analyzed (4). If an increase in spasticity is observed, it should be considered that there may be additional problems (5).

The quantitative evaluation method of spasticity (Table 1) are significant both for the treatment plan and for the measurement of response to treatment. However, this method is quite difficult and it has a tendency to depend on the person making the measurement. Besides, the fact 
that spasticity may differ from day to day, and even within the same day, makes the measurement harder.

\section{Clinical Scales}

A large number of clinical scales are used to evaluate spasticity and/or the related situations (8). Frequently used scales are shown in Table 2. The most well-known and commonly used scale is Ashworth scale (AS) (Table 3). This scale grades the muscle tone from 0 (normal) to 4 (severe spasticity). The usage of this scale is easy; however, the results depend on the evaluator. Later, Modified Ashworth Scale (MAS) has been developed with some additions to the Ashworth Scale (Table 4). It has been a scale commonly preferred because it can be applied easily in a clinical environment, it does not require any tool and it is safe when applied by the same evaluator. However, AS and MAS cannot measure the features that separate spasticity from other tonus disorders (9). Besides, changes that the evaluator makes in the stretching speed may change the measurement results because spasticity depends on speed. However, these are still the most commonly used scales (9).

In the study by Lechner $\mathrm{HE}$ and his friends (10) on the patients with spinal cord injuries, AS is compared with the self-evaluations made by applying patients' spasm frequency scale (SFS) and visual analog scale (VAS). They state that when patients evaluate themselves, they can tell the difference between muscular tonus that is related to spasticity and the muscle tone that affects sensory nervous system, and this distinction may contribute to the proper treatment approach (10).

One of the scales that evaluate spasticity with the passive motion is Tardieu Scale. Passive stretch is performed in the same, lower or higher speed of the fall of extremity segments with gravity. Modified Tardieu Scale (MTS) has been developed by adding to Tardieu Scale the extremities' evaluation positions and the angle of spasticity (Table 5) (11). Numanoglu compared MAS and MTS in spasticity measurements in children with cerebral palsy, and stated that MTS is a more reliable method of measurement (12). In a study, in which MTS and MAS are compared on patients with brain injury and impaired consciousness because of various reasons, MTS has been found as the most reliable method among both measurements and implementers (13). Recently, in another study conducted on patients with spinal cord injuries, it is reported that MAS is sufficient for the evaluation of lower extremities, MTS's reliability among the evaluators and repeatability is excellent and it can be used as a supplementary tool when the treatment decision is taken (14).

Fugl Meyer Scale (FMS) is a scale in which spasticity is evaluated with many parameters like the sense of touch and pain, and the joint position sense of hand, wrist, and body posture (Table 6). Its reliability among the evaluators is high. With FMS, in patients with stroke, a strong correlation between the reduction in motor function and the severity of spastic tonus was demonstrated (15). As with most scales, its use in patients with mild motor impairment is limited by ceiling effect. Gladstone has stated that it is more reliable to use the FMS as an engine scale, because parts of the FMS outside the motor scale (such as pain and sensation) may distract the FMS from being objective (16).

Recently, the scales that can be applied on patients with MS have been developed; these scales are the Multiple Sclerosis Spasticity Scale (MSSS88), the Patient-reported Impact of Spasticity Measure (PRISM), Multiple Sclerosis Impact Scale29 (MSIS29) and Multiple Sclerosis Walking Scale (MSWS12) (17-20). MSSS88 is a scale that evaluates not only the spasticity but also the daily life activities and the social functions with 88 items in 8 different categories (17). However, it takes a long time and this affects the patient's attention and compliance in a negative way. PRISM is a reliable scale with 44 items, it is used to measure the impact of spasticity on life quality of patients with spinal cord injuries (18).
Table 1. Spasticity measurement methods

\section{Clinical scales}

2. Biomechanical methods

- Pendulum test

- Isokinetic dynamometers

3. Neurophysiological-Electrophysiological methods

$\cdot \mathrm{H}$ response

$\cdot \mathrm{H} / \mathrm{M}$ ratio

- F Response, F / M ratio

- Other reflex studies

4. Walking analysis methods

- Dynamic EMG

- Kinematic and kinetic registration

5. New methods

- Elastography

- Myotonometry

Table 2. Spasticity and frequently used scales in related situations

1. Ashworth Scale

2. Modified Ashworth Scale

3. Penn Spasm Frequency Scale

4. Spasm Severity Scale

5. Hygiene Scale

6. Evaluation of deep tendon reflexes Scale

7. Clonus Score

8. Plantar stimulation response Scale

9. Fugyl Meyer Scale

10. Disability Assessment Scale

11. Tone Assessment Scale

12. Tardieu/Modified Tardieu Scale

13. Barthel Index, Functional Independence Scale

14. Multiple Sclerosis Spasticity Scale, MSSS-88

Table 3. Ashworth Scale

0. Normal muscle tone

1. Slight increase in muscle tone, minimal resistance at the end of the range of motion when the extremity is moved (less than half of the EHA)

2. More pronounced tonus increase (the majority of the EHA) felt throughout the entire limb movement in muscle tone

3. Significant tonus increase which makes passive movement difficult

4. Affected extremity flexion and rigidity in extension

\section{Table 4. Modified Ashworth Scale}

0. No tonus increase

1. The presence of a catch-and-release feeling at the end of the range of motion or a slight tonus increase in character with minimal resistance

1+. There is a slight increase in muscle tone observed through minimal resistance throughout the less than half of the joint range of motion

2. Muscle tone is increased throughout the range of motion of the whole joint, but the joints can be moved easily

3. There is significant tonus increase which makes passive movement difficult

4. Affected parts are rigid in flexion and extension

MSIS29 is a life quality scale designed especially for MS; it is designed to be used especially in clinical investigations; the usage of this scale has been increasing gradually, it has two subgroups that evaluate physical and psychological conditions (19). MSWS12 is a good and a reliable scale 


\section{Table 5. Modified Tardieu Scale}

\section{Muscle reaction quality $(X)$}

0 - No resistance during passive motion

1- Minimal resistance during passive motion, no sense of catching at a certain angle

2- Feeling of catching at a certain angle (cuts passive movement, relaxes afterwards)

3- Weakening clonus (less than 10 seconds when stretching is continued and occurs at a certain angle)

4- Strong clonus (longer than 10 seconds when stretching is continued and emerging at a certain angle)

5- The joint can not be moved

\section{Stretching Speed:}

V1: As slow as possible, slower than the natural drop of the extremity segment due to gravity effect

V2: Extremity segment at the natural deceleration rate due to gravity effect

V3: As fast as possible, faster than the natural fall of the extremity segment due to gravity

\section{Table 6. Fugl-Meyer Scale}

\section{Shoulder, elbow, forearm and lower extremity movement \\ I- Muscle stretching reflexes can be obtained \\ II- Voluntary movement is done with dynamic flexor / elevator synergy \\ III- Voluntary movement is made by comparing dynamic flexor / elevator synergies \\ IV- There is little or no need for synergies to make voluntary movements}

V- Normal muscle stretching reflexes

Wrist function - stability, flexion, extension, circumduction

Hand function

General flexion, general extension, five different grips

Coordination and speed-tremor, dysmetry and speed assessment

Finger-nose test, heel-calf test

Balance

Non-supported seating

Parachute reaction-unaffected and on the affected side

Standing-assisted and unsupported

Standing on the affected side and on the unaffected side

Sense-touch, sense of position

Passive joint movement, joint pain

that measures the MS patients' capability of walk, on which the spasticity can easily reveal its effect (20).

While evaluating the functions that spasticity may damage, the usage of the scales that evaluate the functional conditions (Barthel Index, Functional Independence Scale, etc.) is useful for clinical and treatment observation. However, for a better evaluation, functional scales and the scales that evaluate the spasticity and strength should be combined.

\section{Biomechanical Evaluation}

Biomechanical measurements give a controlled warning to the patient and measure mechanical response to motion using, torque, position sensors and electromyography (EMG). Biomechanical measurements correlate with clinical measurements and are reproducible, consistent, and objective. Because of the need for complex and expensive devices, their use has not been widespread, but is limited to research (21).
The pendulum test is based on the oscillation features of an extremity in free circulation. Resistance of loose extremities to forced movement reflects the degree of spastic hypertonia in the quadriceps and hamstring muscles. While the patient is in the supine position, the spastic lower extremity is hanged down by the distal thigh level from the edge of the table. As the extremity is released in the extension position, the pendulum knee motion is assessed by electrogoniometer, while the movement rate is measured by tachometer. Sinusoidal pattern is observed. The slowing of the free oscillation and the dimming in the extremity are in favor of the increase in tonus. In studies with pendulum test in healthy volunteers and patients with spinal cord injuries $(\mathrm{SCl})$, spasticity was found statistically significant in patients with $\mathrm{SCl}(22)$. The pendulum test was also examined in other diseases and was found to be useful for measuring mechanical changes in the knee (23).

Isokinetic dynamometers provide a significant advantage in objective measurement of spasticity as strain rate and amplitude can be standardized. The rested and loose extremity of the patient is passively moved at specific angular velocities and the resistance to movement is measured. It is evaluated with units such as "peak torque", "torque", "work", "threshold angle". It is recommended that measurements should be made on at least two different days with 3 replicates per test. As the speed increases, the increase in torque values is indicative of spasticity. In a study in which isokinetic dynamometers were used and resistance to flexion and extension at different angular velocities was evaluated, significant increase in torque was shown in patients with spinal cord lesions (24). However, Perell et al. (25) did not find any difference between flask patients and normal subjects, although they found similar findings in patients with spinal cord lesions. Pisano et al. (26) showed that the stretch reflex threshold of spasticity due to stroke was significantly lower than the normal individuals, and the results were consistent with the Ashworth Scale. Subsequent studies in stroke patients have supported these findings $(27,28)$.

\section{Electrophysiological Evaluation}

The vast majority of our knowledge about spasticity mechanisms has been obtained from electrophysiological studies (29). H-reflex (Hofmann reflex) is the most commonly used electrophysiological method in evaluating spasticity. The $\mathrm{H}$ reflex indicates the level of excitability of the alpha motor neuron pool directly associated with the spinal column. As the stimulation intensity increases, the $\mathrm{H}$-reflex amplitude increases, and the $\mathrm{M}$-response appears within 3-5 ms following stimulation (21). The $M$ response is the result of the discharge of all the alpha motor neurons in the spinal cord of the muscle, with direct stimulation of the muscle efferent nerve (21). The latency of the H-reflex does not change, but the amplitude and the $\mathrm{H} / \mathrm{M}$ ratio increases in spasticity (21). In addition, F-responses obtained by supramaximal stimulation of peripheral nerves, which are less commonly used in spasticity measurements in practice, are another method of evaluation. They are small amplitude responses that appear after the $M$-response resulting from the antidromic activation of a certain number of motor neurons. The F/M ratio increases in spastic patients (21).

The results obtained from non-standardized H-reflex or electrophysiological testing are not considered specific to spasticity.Although there was a moderate correlation between electrophysiological tests and clinical scales (AS, MAS) in several studies, no correlation was found in most of the studies $(30,31)$. For this reason, electrophysiological measurement methods can be said to be complementary objective methods rather than being used alone (32).

\section{Gait Analysis Methods}

Spasticity is one of the problems that reducing the quality of life of patients with MS. All components of motor impairment (motor loss, spasticity, co-contraction, sensory loss, contracture) should be determined in 
order to evaluate the spastic lower extremities. Optoelectronic motion analysis systems, force platforms, multi-channel EMG devices are used for quantitative gait analysis (33).

Today, kinetic and kinematic measurements have become more practical and useful thanks to portable and wearable devices. Owing to the sensors, static and dynamic acceleration can be measured, with the devices capable of perceiving the slope and posture analysis can be made easier. At this point, the response to the treatment can be easily monitored and the risks of falling have become able to be reduced.

Twenty three studies on the reliability of three-dimensional kinematic gait analysis have been systematically reviewed by McGinley (34). This study has shown that gait analysis errors are acceptable but should not be overlooked when interpreting clinical data (34). It is hoped that new methods developed with functional calibration techniques will further reduce gait analysis errors.

\section{New Methods}

In patients with MS, spasticity measurement is commonly performed with clinical scales, even though there are objective methods. There is a need for objective and more practical new methods that can identify and follow spasticity early.

Elastography is a new way of visualizing the flexibility of biological tissues and is often used to detect malignant lesions in the tissues, such as thyroid, breast tissues, etc (35). Lately it has also been used to measure the flexibility of muscles, tendons and nerves. It is also known as compression elastography, sonoelastography, or real-time ultrasound elastography (RTHE) (36). RTHE and AS were compared in a single-center pilot study where the evaluator was blinded to measure spasticity in patients with MS. In this study, Muscle Elastography Multiple Sclerosis Scores (MEMSs) were used for the first time. MEMSs has been shown to correlate well with commonly used AS to measure MS spasticity $(37,38)$. In another study of the same investigators, numeric rating scale (NRS) and RTHE were compared to monitor treatment response in MS patients who received spasticity therapy $(37,38)$. Both methods were found to be in perfect correlation with each other.

Elastography can open a new page in early diagnosis of spasticity in MS patients and assess the efficacy of spasticity therapy (38). However, extensive and randomized, multicenter clinical trials are required for the validation of this method.

Myotonometry is a new technique which allows objective assessment of muscle spasticity by quantifying tissue displacement response to a standard measuring perpendicular compression force. Besides neurological disorders, it has also been used to investigate changes in muscle tissues of patients such as scoliosis and dull shoulder $(38,39)$. The validity and reliability of the myotonometry technique was tested with various studies and compared with the conventional methods used for spasticity measurement (40-43). It has been suggested that it is a sensitive method to be used in daily clinical practice.

The greatest limitations of elastography, myotonometry, electrophysiological and biomechanical measurements are the lack of a wellequipped laboratories and experienced practitioners. Therefore, it is not as widespread as clinical scales.

\section{CONCLUSION}

The identification and measurement of spasticity is mainly based on the assessment at patient's resting position. However, disorders causing spasticity related to daily life activities are pathological conditions which become evident during voluntary movements. Therefore, quantitative assessment of spasticity is difficult. Evaluation of spasticity should be based on clinical assessment with additional repeated biomechanical and/or electrophysiological measurements obtained during active and functional movements as complementary techniques. In addition, the patient should also be allowed to self-assess his or her symptoms. The objective during development of new measurement methods should be to provide measurement with minimal bias and errors which may affect interpretation.

Presentation: 2. Physical Disability Measurement in Multiple Sclerosis Symposium (1920 May 2018 Izmir, Turkey) are presented.

Peer-review: Externally peer-reviewed.

Conflict of Interest: No conflict of interest was declared by the author.

Financial support: This work was not supported by any research fund.

\section{REFERENCES}

1. Barnes MP, Kent RM, Semlyen JK, McMullen KM. Spasticity in multiple sclerosis. Neurorehabil Neural Repair 2003;17:66-70. [CrossRef]

2. Young RR. Spasticity: A review. Neurology 1994;44:S12-20.

3. Burridge JH, Wood DE, Hermens HJ, Voerman GE, Johnson GR, van Wijck F, Platz T, Gregoric M, Hitchcock R, Pandyan AD. Theoretical and methodological considerations in the measurement of spasticity. Disabil Rehabil 2005;27:69-80. [CrossRef]

4. Burke D, Wissel J, Donnan GA. Pathophysiology of spasticity in stroke. Neurology 2013;80:S20-26. [CrossRef]

5. Özcan O, Sivrioğlu S. Spastisite. In: Oğuz H, Dursun E, Dursun N, editörler. Tıbbi Rehabilitasyon. İstanbul, Nobel Matbaacılık; 2004. pp.723-740.

6. Hutchinson B. What is spasticity and what causes it? MS in Focus 2008;12:6-8.

7. Malhotra S, Pandyan AD, Day CR, Jones PW, Hermens H. Spasticity, an impairment that is poorly defined and poorly measured. Clin Rehabil 2009;23:651-658. [CrossRef]

8. Platz T, Eickhof C, Nuyens G, Vuadens P. Clinical scales for the assessment of spasticity, associated phenomena, and function: a systematic review of the literature. Disabil Rehabil 2005;27:7-18. [CrossRef]

9. Fleuren JFM, Voerman GE, Erren-Wolters CV, Snoek GJ, Rietman JS, Hermens $\mathrm{HJ}$, Nene AV. Stop using the Ashworth Scale for the assessment of spasticity. J Neurol Neurosurg Psychiatry 2010;81:46-53. [CrossRef]

10. Lechner $\mathrm{HE}$, Frotzler A, Eser P. Relationship between self- and clinically rated spasticity in spinal cord injury. Arch Phys Med Rehabil 2006;87:15-19. [CrossRef]

11. Haugh $A B$, Pandyan AD, Johnson GR. A systematic review of the Tardieu Scale for the measurement of spasticity. Disabil Rehabil 2006;28:899-907. [CrossRef]

12. Numanoğlu A, Günel MK. Intraobserver reliability of modified Ashworth scale and modified Tardieu scale in the assessment of spasticity in children with cerebral palsy. Acta Orthop Traumatol Turc 2012;46:196-200. [CrossRef]

13. Mehrholz J, Wagner K, Meissner D, Grundmann K, Zange C, Koch R, Pohl M. Reliability of the Modified Tardieu Scale and the Modified Ashworth Scale in adult patients with severe brain injury: a comparison study. Clin Rehabil 2005;19:751-759. [CrossRef]

14. Akpinar P, Atici A, Ozkan FU, Aktas I, Kulcu DG, Sarı A, Durmus B. Reliability of the Modified Ashworth Scale and Modified Tardieu Scale in patients with spinal cord injuries. Spinal Cord 2017;55:944-949. [CrossRef]

15. Pandian S, Arya KN. Stroke-related motor outcome measures: do they quantify the neurophysiological aspects of upper extremity recovery? J Bodyw Mov Ther 2014;18(3):412-423. [CrossRef]

16. Gladstone DJ, Danells CJ, Black SE. The Fugl-Meyer Assessment of Motor Recovery after Stroke: A Critical Review of Its Measurement Properties. Neurorehabil Neural Repair 2002;16(3):232-240. [CrossRef]

17. Hobart JC, Riazi A, Thompson J, Styles IM. Ingram W, Vickery PJ, Warner M, Fox PJ, Zajicek JP. Getting the measure of spasticity in multiple sclerosis: the Multiple Sclerosis Spasticity Scale (MSSS88). Brain 2006;129:224-234. [CrossRef]

18. Cook KF, Teal CR, Engebretson JC, Hart KA, Mahoney JS, Robinson-Whelen S Sherwood AM. Development and validation of Patients reported Impact of Spasticity Measure (PRISM). J Rehabil Res Dev 2007;44:363-371. [CrossRef] 
19. Hobart J, Lamping D, Fitzpatrick R, Riazi A, Thompson AJ. The Multiple Sclerosis Impact scale (MSIS29): a new patient-based outcome measure. Brain 2001;124:962-973. [CrossRef]

20. McGuigan $C$, Hutchinson M. Confirming the validity and responsiveness of the multiple sclerosis walking scale-12(MSWS-12). Neurology 2004;62:21032105. [CrossRef]

21. Katz RT, Dewald JPA, Schmit BD. Spasticity. In: Braddom RL, editor. Physical Medicine and Rehabilitation 2nd ed. Philadelphia, W. B. Saunders Company; 2000. pp.592-615.

22. Joghtaei M, Arab AM, Hashemi-Nasl H, Joghataei MT, Tokhi MO. Assessment of passive knee stiffness and viscosity in individuals with spinal cord injury using pendulum test. J Spinal Cord Med 2015;38:170-177. [CrossRef]

23. Valle MS, Casabona A, Sgarlata R, Garozzo R, Vinci M, Cioni M. The pendulum test as a tool to evaluate passive knee stiffness and viscosity of patients with rheumatoid arthritis. BMC Musculoskelet Disord 2006;7. [CrossRef]

24. Firoozbakhsh KK, Kunkel CF, Scremin AM, Moneim MS. Isokinetic dynamometric technique for spasticity assessment. Am J Phys Med Rehabil 1993;72:379-85. [CrossRef]

25. Perell K, Scremin A, Scremin O, Kunkel C. Quantifying muscle tone in spinal cord injury patients using isokinetic dynamometric techniques. Spinal Cord 1996;34:46-53. [CrossRef]

26. Pisano F, Miscio G, Del Conte C, Pianca D, Candeloro E, Colombo R. Quantitative measures of spasticity in poststroke patients. Clin Neurophysiol 2000;111:1015-1022. [CrossRef]

27. Starsky AS, Sangani SG, McGuire JR, Logan B, Schmit BD. Reliability of biomechanical spasticity measurements at the elbow of people poststroke. Arch Phys Med Rehabil 2005;86:1648-1654. [CrossRef]

28. Kim DY, Park Cl, Chon JS, Ohn JS, Park TH, Bang IK. Biomechanical assessment with electromyography of post-stroke ankle plantar flexor spasticity. Yonsei Med J 2005;46:546-554. [CrossRef]

29. Voerman GE, Gregoric M, Hermens HJ. Neurophysiological methods for the assessment of spasticity: The Hoffmann reflex, the tendon reflex, and the stretch reflex. Disabil Rehabil 2005;27:33-68. [CrossRef]

30. Sherwood AM, Graves DE, Priebe MM. Altered motor control and spasticity after spinal cord injury: Subjective and objective assessment. J Rehabil Res Dev 2000;37:41-52.

31. Biering-Sorensen F, Nielsen JB, Klinge K. Spasticity assessment: A review. Spinal Cord 2006;44:708-722. [CrossRef]
32. Yablon SA, Stokic DS. Neurophysiologic evaluation of spastic hypertonia: implications for management of the patient with intrathecal baclofen pump. Am J Phys Med Rehabil 2004;83:S10-S18. [CrossRef]

33. Möhür $H$, Akkuş S. Normal ve Patolojik Yürüme. In: Oğuz $H$, Dursun $E$ Dursun N, editors. Tıbbi Rehabilitasyon. Istanbul, Nobel Tıp Kitabevleri; 2004. pp.265-279.

34. McGinley JL, Baker R, Wolfe R, Morris ME. The reliability of threedimensional kinematic gait measurements: a systematic review. Gait Posture 2009;29:360-369. [CrossRef]

35. Illomei G. Muscle elastography in multiple sclerosis spasticity. Neurodegener Dis Manag 2016;6:13-16. [CrossRef]

36. Drakonaki EE, Allen GM, Wilson DJ. Ultrasound elastography for musculoskeletal applications. Br. J. Radiol 2012;85:1435-1445. [CrossRef]

37. Illomei G, Spinicci G, Locci E, Marrosu MG. Muscle elastography: a new imaging technique for multiple sclerosis spasticity measurement. Neurol Sci 2017;38:433-439. [CrossRef]

38. Oliva-Pascual-Vaca, A. Heredia-Rizo AM, Barbosa-Romero A, Oliva-PascualVaca J, Rodríguez-Blanco C, Tejero-García S. Assessment of paraspinal muscle hardness in subjects with a mild single scoliosis curve: a preliminary myotonometer study. J Manipulative Physiol Ther 2014;37:326-333. [CrossRef]

39. Hung CJ, Hsieh CL, Yang PL, Lin JJ. Relationships between posterior shoulder muscle stiffness and rotation in patients with stiff shoulder. J Rehabil Med 2010;42:216-220. [CrossRef]

40. Leonard CT, Deshner WP, Romo JW, Suoja ES, Fehrer SC, Mikhailenok EL. Myotonometer intra- and interrater reliabilities. Arch Phys Med Rehabil 2003;84:928-932. [CrossRef]

41. Leonard CT, Stephens JU, Stroppel SL. Assessing the spastic condition of individuals with upper motorneuron involvement: validity of the myotonometer. Arch Phys Med Rehabil 2001;82:1416-1420. [CrossRef]

42. Leonard CT, Brown JS, Price TR, Queen SA, Mikhailenok EL. Comparison of surface electromyography and myotonometric measurements during voluntary isometric contractions. J Electromyogr Kinesiol 2004;14:709-714. [CrossRef]

43. Li X, Shin H, Li S, Zhou P. Assessing muscle spasticity with Myotonometric and passive stretch measurements: validity of the Myotonometer. Sci Rep 2017;7. [CrossRef] 